\title{
Solubilization and Stability of Mitomycin C Solutions Prepared for Intravesical Administration
}

\author{
Alan L. Myers ${ }^{1} \cdot$ Yan-Ping Zhang $^{1} \cdot J^{\text {Jitesh D. Kawedia }}{ }^{1} \cdot$ Ximin Zhou $^{1}$ • \\ Stacey M. Sobocinski ${ }^{2} \cdot$ Michael J. Metcalfe ${ }^{3} \cdot$ Mark A. Kramer $^{1}$. \\ Colin P. N. Dinney ${ }^{3}$ Ashish M. Kamat ${ }^{3}$
}

Published online: 3 May 2017

(c) The Author(s) 2017. This article is an open access publication

\begin{abstract}
Background Mitomycin C (MMC) is an antitumor agent that is often administered intravesically to treat bladder cancer. Pharmacologically optimized studies have suggested varying methods to optimize delivery, with drug concentration and solution volume being the main drivers. However, these MMC concentrations (e.g. $2.0 \mathrm{mg} / \mathrm{mL}$ ) supersede its solubility threshold, raising major concerns of inferior drug delivery.

Objective In this study, we seek to confirm that the pharmacologically optimized MMC concentrations are achievable in clinical practice through careful modifications of the solution preparation methods.

Methods MMC admixtures (1.0 and $2.0 \mathrm{mg} / \mathrm{mL}$ ) were prepared in normal saline using conventional and alternative compounding methods. Conventional methodology resulted in poorly soluble solutions, with many visible
\end{abstract}

Alan L. Myers

almyers@mdanderson.org

Jitesh D. Kawedia

jdkawedia@mdanderson.org

Ximin Zhou

xzhou10@mdanderson.org

Stacey M. Sobocinski

smlavsa@mdanderson.org

Michael J. Metcalfe

mjmetcalfe@mdanderson.org

Colin P. N. Dinney

cdinney@mdanderson.org

Ashish M. Kamat

akamat@mdanderson.org particulates and crystallates. However, special compounding methods, which included incubation of solutions at $50{ }^{\circ} \mathrm{C}$ for $50 \mathrm{~min}$ followed by storage at $37^{\circ} \mathrm{C}$, were sufficient to solubilize drug. Chemical degradation of MMC solutions was determined over $6 \mathrm{~h}$ using high-performance liquid chromatography (HPLC) analytics, while physical stability was tested in parallel.

Results Immediately following the $50 \mathrm{~min}$ incubation, both MMC solutions exhibited approximately 5-7\% drug degradation. Based on the measured concentrations and linear regression of degradation plots, additional storage of these solutions at $37^{\circ} \mathrm{C}$ for $5 \mathrm{~h}$ retained chemical stability criterion $(<10 \%$ overall drug loss). No physical changes were observed in any solutions at any test time points. Conclusion We recommend that the described alternative preparation methods may improve intravesicular delivery of MMC in this urological setting, and advise that

1 Department of Pharmacy Research, The University of Texas MD Anderson Cancer Center, 1515 Holcombe Boulevard, Houston, TX 77030, USA

2 Department of Pharmacy Medication Management and Analytics, The University of Texas MD Anderson Cancer Center, 1515 Holcombe Boulevard, Houston, TX 77030, USA

3 Department of Urology, The University of Texas MD Anderson Cancer Center, 1515 Holcombe Boulevard, Houston, TX 77030, USA 
clinicians employing these changes should closely monitor patients for MMC toxicities and pharmacodynamics (change in clinical outcomes) that result from the potential enhancement of MMC exposure in the bladder.

\section{Key Points}

Under conventional preparation methods, mitomycin $\mathrm{C}$ (MMC) solutions $(\geq 1.0 \mathrm{mg} / \mathrm{mL})$ intended for intravesical delivery are poorly solubilized, raising concerns of improper drug delivery to the bladder.

MMC intravesical solutions ( 1 and $2 \mathrm{mg} / \mathrm{mL}$ ) prepared by alternative methods to improve their solubility, as outlined in this study, retain sufficient physical and chemical stability for up to $5 \mathrm{~h}$.

\section{Introduction}

Bladder cancer is the seventh most common cancer worldwide in men (17th most common among women), with the majority of patients presenting with nonmuscle invasive disease [1]. These cases are generally managed with a combination of transurethral resection and intravesical immunotherapy or chemotherapeutic agents [2]. Mitomycin C (MMC) is a chemotoxic agent widely used for the treatment of solid tumors, such as carcinomas of the breast, esophagus, cervix, and bladder [3]. For nonmuscle invasive bladder cancer (NMIBC), MMC, used as a single agent perioperatively, has been shown to reduce the likelihood of tumor recurrence by up to $35 \%$ [4]. MMC has also demonstrated benefit in preventing recurrence through the use of long-term maintenance regimens [5], or in combination with other therapeutic agents [6]. It has previously been shown that intravesical delivery of MMC to the bladder is affected by its dose and pharmacokinetics, as well as residual urine volume, urine production, dosing volume, urine $\mathrm{pH}$ and dwell time; optimization of these parameters improves drug efficacy and oncologic outcomes [6-8]. Based on level 1 evidence (systematic review of randomized controlled trials), the suggested optimal concentration of MMC by the intravesical route is $2.0 \mathrm{mg} / \mathrm{mL}(40 \mathrm{mg} / 20 \mathrm{~mL})$, which reduced the recurrence of bladder carcinomas by $42.6 \%$, compared with $23.5 \%$ in patients treated with $1.0 \mathrm{mg} / \mathrm{mL} \quad(20 \mathrm{mg} / 20 \mathrm{~mL})$ solutions of MMC [7]. However, this recommendation is not universal among urology oncologists [9-15], and one major reason for avoiding the higher MMC doses in this surgical setting is the lack of drug stability information in this concentration range.

There are various manufactured products of MMC with reported stability data of solutions $<1.0 \mathrm{mg} / \mathrm{mL}$. For example, stability was reported on intravenous formulations, which, in addition to the active ingredient MMC, also contain low concentrations of mannitol as a bulking agent [16]. The authors reported that MMC $0.4 \mathrm{mg} / \mathrm{mL}$ intravenous admixtures prepared in $0.9 \%$ normal saline (NS) diluent were stable up to $24 \mathrm{~h}$ [16]. However, MMC intravenous solutions of $0.4 \mathrm{mg} / \mathrm{mL}$ were poorly stable in dextrose $5 \%$ water (D5W) diluent-approximately $2 \mathrm{~h}$ when stored in commonly used polyvinyl chloride (PVC) intravenous bags [16]. A generic manufacturer product of MMC, which also contains mannitol, has reported stability information. When MMC powder is reconstituted with sterile water for injection to a final concentration of $0.5 \mathrm{mg} / \mathrm{mL}$, the infusion solution is stable up to 7 days when stored at room temperature [17]. Diluted in NS or sodium lactate injection, $40 \mu \mathrm{g} / \mathrm{mL}$ intravenous solutions of MMC are stable up to 12 and $24 \mathrm{~h}$, respectively [17].

In a published study, the stability of another MMC formulation, which contains sodium chloride but no mannitol, was reported [18]. Their work demonstrated that infusion solutions prepared in sterile water for injection to a concentration of $0.8 \mathrm{mg} / \mathrm{mL}$ were stable up to 4 days at room temperature, but notable precipitation of MMC drug occurred after 1 day of storage in the refrigerator $\left(4{ }^{\circ} \mathrm{C}\right)$ [18]. In addition, intravenous solutions of $0.6 \mathrm{mg} / \mathrm{mL}$ prepared in NS were stable for up to 4 days at room temperature and under refrigeration [18]. Moreover, MMC infusion solutions of $1.0 \mathrm{mg} / \mathrm{mL}$ prepared in phosphate-buffered saline were stable when stored at room temperature for at least 7 days, but rapidly precipitated under refrigeration [18]. Kinast et al. recently assessed the chemical stability of MMC $0.4 \mathrm{mg} / \mathrm{mL}$ solutions prepared in sterile water for ophthalmic delivery while stored under various cooling conditions [19]. After warming to room temperature, all solutions were chemically stable for at least $24 \mathrm{~h}$ [19].

At our cancer center, we prepare MMC admixtures for intravesicular delivery from a generic product manufacturer. Neither the generic manufacturer nor a published study [16] provide stability data for MMC solutions $>0.5 \mathrm{mg} / \mathrm{mL}$ that also contain mannitol. In some clinical settings, including at our center, intravesical administration of MMC is recommended at $2.0 \mathrm{mg} / \mathrm{mL}$ $(40 \mathrm{mg} / 20 \mathrm{~mL})$ to achieve optimal delivery and outcomes $[7,20]$; however, there are no published stability data on these higher concentrated solutions. Therefore, the aim of the present study was to determine the stability of MMC solutions (1.0 and $2.0 \mathrm{mg} / \mathrm{mL})$ commonly used during intravesical therapy for the treatment of bladder cancer. 


\section{Materials and Methods}

\subsection{Reagents}

MMC reference standard ( $>99 \%$ purity; Lot 12362 ) was purchased from MedChem Express (Monmouth Junction, NJ, USA). MMC for Injection USP, $40 \mathrm{mg}$ amber vial, lyophilized powder (Accord Healthcare, Inc., Lot PS00649, Exp. 02/2017), and $0.9 \%$ sodium chloride in $250 \mathrm{~mL}$ Excel $^{\circledR}$ bags (Baxter Healthcare, Lot J5K206, Exp. 02/18) were both obtained from the Division of Pharmacy, MD Anderson Cancer Center (Houston, TX, USA). The chemical solvents and reagents used to prepare the mobile phase were high-performance liquid chromatography (HPLC) grade (or greater) and included acetonitrile, methanol, sodium dihydrogen phosphate, and sodium hydroxide. All HPLC reagents and solvents were purchased through Fisher Scientific (Waltham, MA, USA). Water was obtained from a Milli-Q ultrapure water purification system (Millipore, Bedford, MA, USA).

\subsection{Preparation of Mitomycin C Intravesicular Solutions}

For the $2.0 \mathrm{mg} / \mathrm{mL}$ solutions, $40 \mathrm{mg}$ of MMC for Injection (lyophilized powder) was reconstituted with $20 \mathrm{~mL}$ of NS in its original manufacturer-supplied, amber-colored vial. MMC did not fully dissolve following reconstitution under these conditions at room temperature (data not shown). Since heat can enhance drug solubility, preliminary attempts to solubilize MMC were conducted at $37{ }^{\circ} \mathrm{C}$; however, at this temperature, the reconstituted $\mathrm{MMC}$ $2.0 \mathrm{mg} / \mathrm{mL}$ solutions did not dissolve after more than $2 \mathrm{~h}$ of incubation (data not shown). We further found that solutions did dissolve after a $50 \mathrm{~min}$ incubation time period at $50{ }^{\circ} \mathrm{C}$, therefore this temperature was used in further physical and chemical stability tests; however, microparticulates formed when the temperature cooled down from $50{ }^{\circ} \mathrm{C}$ to room temperature after $1-2 \mathrm{~h}$ (data not shown).

Reconstituted $2.0 \mathrm{mg} / \mathrm{mL}$ vials were placed in a Model 75 D Water Bath (VWR International, Radnor, PA, USA) at $50{ }^{\circ} \mathrm{C}$ for 50 min to yield a homogenous solution. During this incubation, vials were gently shaken by hand for $30 \mathrm{~s}$ every $10 \mathrm{~min}$. After $50 \mathrm{~min}$, the solutions were transferred to a $50 \mathrm{~mL}$ plastic syringe (Becton Dickinson, Franklin Lakes, NJ, USA) and stored at $37{ }^{\circ} \mathrm{C}$, to avoid particulate formation, in an Imperial III incubator oven (Lab-Line, Melrose Park, IL, USA). Triplicate sample solutions were prepared.

For the $1.0 \mathrm{mg} / \mathrm{mL}$ solutions, $40 \mathrm{mg}$ of $\mathrm{MMC}$ for Injection (lyophilized powder) was reconstituted with $40 \mathrm{~mL}$ of NS in its original vial. Further preparation of these solutions was similar to the $2.0 \mathrm{mg} / \mathrm{mL}$ solutions.

\subsection{Design of the Stability Study}

For this descriptive, laboratory-based physicochemical stability study, a series of three independent syringes were prepared for each tested concentration. An aliquot $(4 \mathrm{~mL})$ of solution was withdrawn from the syringe immediately following incubation (baseline), and at 1, 2, 3, 4, 5 and $6 \mathrm{~h}$ during storage at $37^{\circ} \mathrm{C}$. MMC solutions were considered physically and chemically stable if there were no changes in physical characteristics, and if $\geq 90 \%$ initial drug concentration ( $\leq 10 \%$ degradation) was retained in samples.

\subsection{Physical Stability}

The physical stability of MMC in test solutions was assessed by visual examination of solutions for color change and precipitation, and by semi-quantitative measurements of turbidity and particle content in the samples. At each sampling time point, an aliquot $(3.5 \mathrm{~mL})$ of sample solution was transferred to a $15 \mathrm{~mL}$ borosilicate glass tube with a polypropylene screw cap. The tubes were previously washed with Milli-Q ${ }^{\circledR}$ water and dried overnight. Physical instability was defined as visible particulate matter, haze, changes in color, or a change in measured turbidity of $\geq 0.5$ nephelometric turbidity units (NTUs).

\subsubsection{Organoleptic Assessment}

The appearance and color of all test solutions were evaluated. In general, MMC solutions dissolved in clear aqueous solutions (e.g. water, NS, D5W) exhibit a characteristic purplish-color. Detection of visible particulates was performed under normal diffuse fluorescent room light with the unassisted eye. Aliquots of test samples were transferred to a glass test tube and then gently swirled for $5 \mathrm{~s}$ to view in front of a white panel, followed by a black panel.

\subsubsection{Tyndall Effect}

Samples without obvious visual incompatibility were further evaluated by a high-intensity monodirectional light. Samples were exposed to a Fiber-Lite Serial 180 Tyndall beam (Dolan-Jenner Industries, Woburn, MA, USA) to qualitatively observe for scattering of light by nonvisible particulates.

\subsubsection{Turbidity Measurements}

Turbidity, the degree to which light is scattered by suspended particles, was measured in NTUs using a colorcorrecting Turbidimeter 2100 AN (Hach Company, Loveland, CO, USA) with a tungsten-filament lamp light source. 
The instrument was calibrated to measure NTUs in the range of $0.001-10,000$. MMC preparations complied with the test if there was a $\leq 0.5 \mathrm{NTU}$ percentage change from baseline recording.

\subsubsection{Particle Determination}

In all samples, subvisible particles ranging in size from 1.2 to $100 \mu \mathrm{m}$ were counted using the HIAC Royco 9703 Liquid Particle Counting System (Hach Ultra Analytics, Grants Pass, OR, USA). The optical design included a light-obscuration sensor that utilized a laser diode as an illuminator. According to United States Pharmacopeial (USP) guidelines [21], MMC solutions complied with the test if the average number of particles present in the samples did not exceed 6000 for particle sizes $\geq 10 \mu \mathrm{M}$, and 600 for particle sizes $\geq 25 \mu \mathrm{M}$.

\subsection{Chemical Stability}

MMC concentrations were determined using a HPLC with ultraviolet wavelength detection (HPLC-UV) method that was demonstrated to be stability-indicating according to previous publications [22-26].

\subsubsection{Chromatographic Conditions}

The assay was conducted on a Waters ${ }^{\circledR} 2695$ Alliance Separation Module (Milford, MA, USA) coupled to a Waters ${ }^{\circledR} 996$ photodiode array detector. The reverse phase column was a Kinetex ${ }^{\circledR} \mathrm{C} 18(150 \mathrm{~mm} \times 4.6 \mathrm{~mm}, 5 \mu \mathrm{m}$; Phenomenex ${ }^{\circledR}$, Torrance, CA, USA), protected by a SecurityGuard cartridge of the same stationary phase material. The mobile phase consisted of $83.5 \%$ of A ( $25 \mathrm{mM}$ sodium phosphate, $\mathrm{pH} 5.4$, adjusted with $1 \mathrm{~N}$ sodium hydroxide) and $16.5 \%$ of B (50\% methanol: $50 \%$ acetonitrile) and delivered isocratically at $0.9 \mathrm{~mL} / \mathrm{min}$. The wavelength of the UV detection was set at $365 \mathrm{~nm}$. The data were acquired and integrated with the Waters ${ }^{\circledR}$ Empower 2 software. Injection volume was $10 \mu \mathrm{L}$. Under these chromatographic conditions, MMC eluted at approximately 4.6 min (Fig. 1a).

\subsubsection{Method Validation}

A reference stock solution of MMC $0.75 \mathrm{mg} / \mathrm{mL}$ was prepared in neat methanol and stored at $-20^{\circ} \mathrm{C}$ in a freezer protected from light exposure. On the day of analysis, the stock solution was diluted further with a mixture of methanol and water in a ratio of 25:75. The same HPLC system and column were used to measure all MMC concentrations.

The stability-indicating capacity of the HPLC method was tested by accelerated degradation of MMC in solutions exposed to heat (water bath at $\left.100{ }^{\circ} \mathrm{C}\right)$, acidic $(0.1 \mathrm{~N} \mathrm{HCl})$, basic $(0.1 \mathrm{~N} \mathrm{NaOH})$, and oxidative (3\% hydrogen peroxide) conditions. We found no interference of the degradation product peaks with the peak of intact drug, demonstrating that the assay was stability-indicating (Fig. 1a-e). Five calibrators of known concentrations $(50,75,100,125$, and $150 \mu \mathrm{g} / \mathrm{mL}$ ) were analyzed to obtain the standard curve using the least square linear regression method. The calibration curve was linear from 50 to $150 \mu \mathrm{g} / \mathrm{mL}$, with a satisfactory correlation coefficient $R^{2} \geq 0.9997$. For three known MMC concentrations, the precision of the assay, determined from six replicate injections, were all $>99.6 \% \pm 0.1 \mu \mathrm{g} / \mathrm{mL}$. Precision, expressed as a percentage of the relative standard deviation, was $<0.12 \%$ for all solutions. The intra- and interday coefficients of variation of the assay were $\leq 0.3 \%$ and $\leq 0.8 \%$, respectively.

\subsection{3 pH Measurements}

Measurements of $\mathrm{pH}$ were performed in triplicate using an Ultra Basic UB-10 pH meter (Denver Instruments, Bohemia, NY, USA). Prior to sample analysis, the meter was calibrated with standard buffer solutions (Thermo Scientific, Chelmsford, MA, USA) of pH 4.01, 7.01, and 10.01.

\subsection{Data Analysis}

MMC solutions were defined as chemically stable if $<10 \%$ was retained from the starting concentration. The percentage of intact drug loss was calculated by the actual drug loss based on the measured concentration at individual time points, as well as from linear regression to determine whether $>10 \%$ drug loss occurred. All the measured concentration versus time data points were utilized in the linear regression analysis calculated using GraphPad Prism ${ }^{\circledR}$ v6.07 (GraphPad Software, Inc., San Diego, CA, USA). Confidence intervals (CIs; 95\%) and standard deviations were used to determine the variability in measured concentrations and to determine the time when drug loss was $>10 \%$. To compare the stability of tested MMC concentrations, the slopes of regression lines from each MMC concentration were compared using analysis of covariance (ANCOVA) by GraphPad Prism ${ }^{\circledR}$ software. The a priori threshold for statistical significance was set at $p<0.05$.

\section{Results}

\subsection{Physical Stability}

Our preliminary studies demonstrated, as expected, that $0.5 \mathrm{mg} / \mathrm{mL}$ solutions readily dissolved in NS (data not 


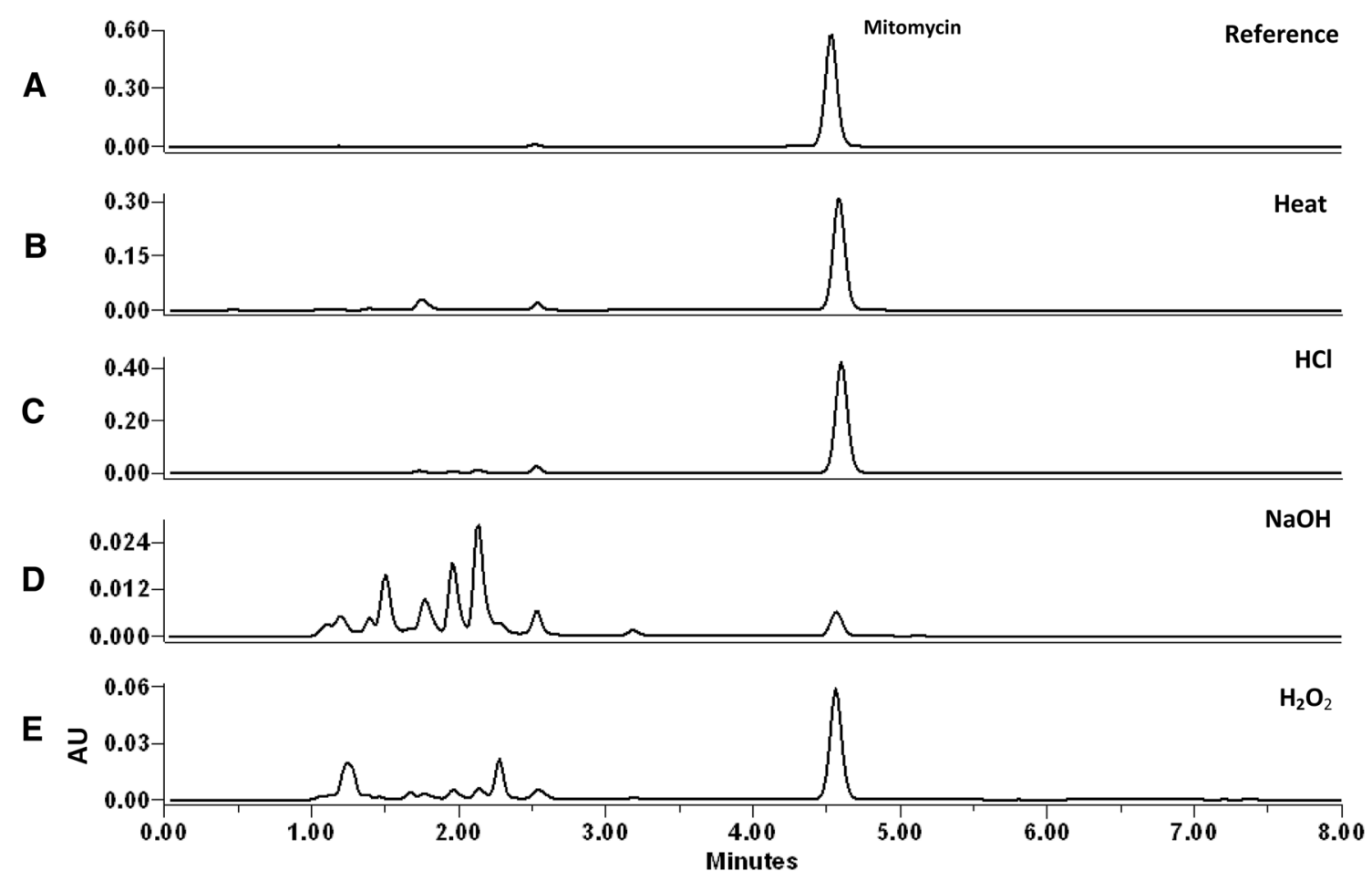

Fig. 1 HPLC-UV chromatograms of a reference MMC solution (a), and following forced degradation by heat $(\mathbf{b})$, acid $(\mathbf{c})$, base $(\mathbf{d})$, and oxidation (e). The timeline and $\mathrm{y}$-axis units in panel $\mathrm{E}$ applies to all

shown); however, we found that immediately following reconstitution with NS, both MMC solutions $-1.0 \mathrm{mg} / \mathrm{mL}$ (40 mg/40 mL NS) and $2.0 \mathrm{mg} / \mathrm{mL}(40 \mathrm{mg} / 20 \mathrm{~mL} \mathrm{NS})$ appeared insoluble. For further evaluation, the reconstituted solutions were transferred from the original amber vial to prewashed, clear glass tubes. All MMC solutions were purplish colored, with numerous undissolved drug particles that were visible with the unaided eye under room light and when exposed to the high-intensity Tyndall beam. Allowing the solution to stand undisturbed for over $2 \mathrm{~h}$ or using vigorous shaking and sonication periods did not produce a dissolved solution.

Using the original manufacturer's amber vial, reconstituted solutions were placed in a $50{ }^{\circ} \mathrm{C}$ hot water bath for $50 \mathrm{~min}$. All resultant MMC solutions were purplish colored, but clear when viewed under normal fluorescence room light, and there was no evidence of precipitation in any of the solutions. When viewed under the Tyndall Beam, some solutions were slightly hazy with few small particulates. For all samples, the measured turbidities were in the ranges of 1.2-1.4 NTUs initially, and increased gradually to above 1.5 NTUs. Changes in turbidities did not exceed 0.5 NTUs (over baseline readings) throughout the $6 \mathrm{~h}$ study period. There was a considerable amount of small particle contents in all the sample solutions initially, with negligible increases over the entire study period. panels. $\mathrm{AU}$ absorbance units, $\mathrm{H}_{2} \mathrm{O}_{2}$ hydrogen peroxide, $\mathrm{HCl}$ hydrochloric acid, $H P L C$ high-performance liquid chromatography, $M M C$ mitomycin $\mathrm{C}, \mathrm{NaOH}$ sodium hydroxide

\subsection{Chemical Stability}

Since the presence of heat in the initial hot water bath incubation could accelerate MMC degradation, we performed chemical stability tests to measure intact drug loss over a $6 \mathrm{~h}$ storage period at $37^{\circ} \mathrm{C}$. For the $1.0 \mathrm{mg} / \mathrm{mL}$ solutions, there was approximately $6-7 \%$ drug loss immediately following the $50 \mathrm{~min}$ incubation period (denoted as ' $0 \mathrm{~h}$ ' in Fig. 2). After $6 \mathrm{~h}$ of storage at $37^{\circ} \mathrm{C}$, there was approximately $2-3 \%$ further drug loss in the $1.0 \mathrm{mg} / \mathrm{mL}$ test solutions (Fig. 2a). Overall, approximately $8-11 \%$ intact drug loss was observed over the entire study period $(6 \mathrm{~h})$ for the $1.0 \mathrm{mg} / \mathrm{mL}$ MMC solutions.

Immediately following the $50 \mathrm{~min}$ incubation period at $50{ }^{\circ} \mathrm{C}$, the $2.0 \mathrm{mg} / \mathrm{mL}$ drug solutions showed slight MMC degradation, with approximately 5-6\% intact drug loss (denoted as ' 0 h' in Fig. 2b). Afterwards, there was approximately $2-4 \%$ greater drug loss during the $6 \mathrm{~h}$ storage period at $37{ }^{\circ} \mathrm{C}$ in the incubator oven (Fig. 2b). Overall, approximately $7-11 \%$ total intact drug loss was observed during the entire study period $(6 \mathrm{~h})$ for the MMC $2.0 \mathrm{mg} / \mathrm{mL}$ solutions.

\subsection{Data Analysis}

For each MMC intravesicular solution ( 1 and $2 \mathrm{mg} / \mathrm{mL}$ ), there were no appreciable changes in any physical stability 


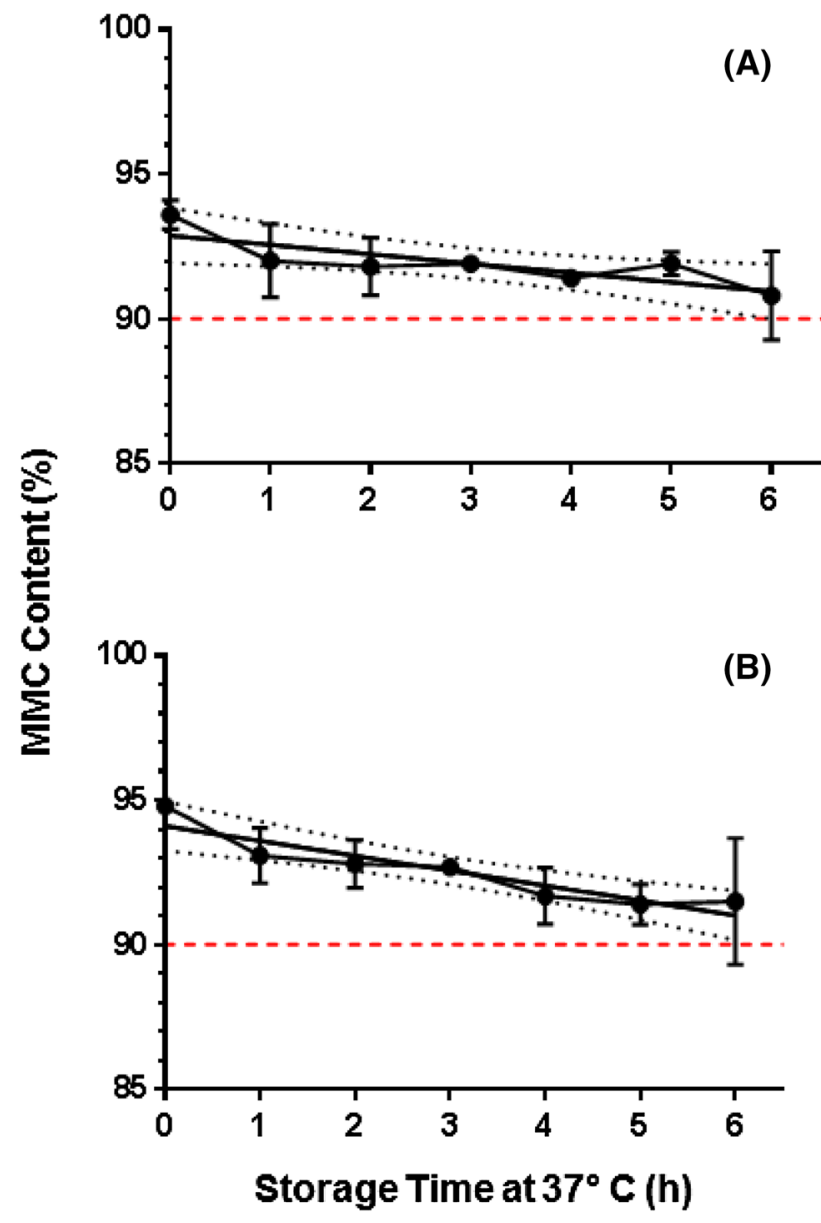

Fig. 2 Chemical stability of MMC $1.0 \mathrm{mg} / \mathrm{mL}$ (a) and $2.0 \mathrm{mg} / \mathrm{mL}$ (b) diluted in $0.9 \%$ sodium chloride and stored at $37{ }^{\circ} \mathrm{C}$. MMC content was monitored over $6 \mathrm{~h}$ (one analysis every $1 \mathrm{~h}$ ). The time zero point represents MMC content immediately following the $50 \mathrm{~min}$ incubation period at $50{ }^{\circ} \mathrm{C}$. Data are expressed as mean $\pm \mathrm{s}-$ tandard deviation $(n=3)$ superimposed with the linear regression line and corresponding $\pm 95 \%$ confidence intervals (represented by dotted lines). MMC mitomycin $\mathrm{C}$

tests; thus, we concluded that both solutions are physically stable for at least $6 \mathrm{~h}$. Based on the lower limit of the $95 \%$ $\mathrm{CI}$, calculated from linear regression and standard deviations, all solutions retained $\geq 90 \%$ intact drug $(\leq 10 \%$ degradation) for $5 \mathrm{~h}$ (Fig. 2a, b). There was no statistically significant difference $(p=0.1932)$ between the slopes of regression lines for the two MMC solutions. Thus, MMC solutions ( 1 and $2 \mathrm{mg} / \mathrm{mL}$ ) were physically and chemically stable up to $5 \mathrm{~h}$.

\section{Discussion}

MMC, an antibiotic first isolated from Streptococcus caespitosus bacterium, is a quinone-containing compound that requires enzymatic bioactivation to a reactive semi- quinone metabolite that is thought to be responsible for the bulk of its cytotoxicity [27]. MMC is of high importance to urologists since it is one of the most common cytotoxic antitumor agents used intravesically, especially in the treatment of NMIBC [6].

Based on the literature, the solubility of MMC at room temperature prepared in water and various other aqueous milieu is approximately $0.9 \mathrm{mg} / \mathrm{mL}$ [28-30]. Nonetheless, in certain bladder cancer patients, urology surgeons utilize MMC preparations in concentrations $\geq 1 \mathrm{mg} / \mathrm{mL}$ [7], which supersede its solubility threshold. For instance, there is strong evidence supporting a pharmacologically 'optimized' concentration of MMC $2.0 \mathrm{mg} / \mathrm{mL}(40 \mathrm{mg} / 20 \mathrm{~mL})$ when administered intravesically, which showed greater efficacy compared with lower concentrated MMC regimens [7]; however, this recommendation is not universally accepted among urology oncologists [9-15], due in part to the lack of MMC stability information at supra-high concentrations. Until now, a full evaluation of the chemical and physical stability of these supra-concentrated MMC solutions, which, prepared under conventional methods, may place the patient at risk for under-drug exposure due to the lack of solubility, was poorly known.

The small volume of diluting solution $(10-20 \mathrm{~mL})$ allows direct preparation of these MMC admixtures in the original manufacturer's vial [7,8]; however, these vials are amber-colored, which may hinder full assessment of solubility by casual inspection, especially when viewed by the unaided eye under normal room light. Allowing the vial to stand undisturbed for several minutes after preparation allows the drug particles to settle to the bottom of vial, possibly rendering these unwanted particulates increasingly difficult to observe by the pharmacy staff.

In our preliminary physical stability experiments (data not shown), both MMC solutions (1.0 and $2.0 \mathrm{mg} / \mathrm{mL}$ ) prepared in these amber vials appeared insoluble, with noticeable visible crystalline precipitates that accumulated on the bottom of the vial, after close inspection by the unaided eye. These preliminary findings raised concerns that pharmacologically optimized concentrations of MMC are often prepared, unintentionally, without prior solubilization, which may have immense practical implications for urologists treating patients with bladder cancer. Hence, these experimental observations were the impetus to further evaluate MMC physical and chemical stability using alternative preparation methods to achieve fuller solubilization.

For both tested concentrations of MMC, we observed approximately $8-10 \%$ drug loss, with no appreciable physical stability decrements, following initial incubation at $50{ }^{\circ} \mathrm{C}$ for $50 \mathrm{~min}$ and during storage in an incubator oven at $37^{\circ} \mathrm{C}$ for $5 \mathrm{~h}$. These novel data support special preparation methods of MMC admixtures used in 
intravesical therapy. For instance, solutions can initially be prepared by reconstitution with NS, followed by incubation at $50{ }^{\circ} \mathrm{C}$ for $50 \mathrm{~min}$. Solutions can then be stored for up to $5 \mathrm{~h}$ at $37^{\circ} \mathrm{C}$ in an intravenous bag warmer prior to administration by the urological surgical team.

Worldwide, various MMC formulations are administered in the urology/oncology setting. In the present study, we tested a manufacturer's product that also contains the inactive (excipient) ingredient mannitol. We predict that our findings, although not specifically studied, are also applicable to other commercially available MMC formulations that lack mannitol. The dose, frequency, and length of MMC intravesical therapy is not fully established. The utility of electromotive drug administration (EMDA) and chemohyperthermia have been investigated, showing some clinical benefit [12, 13, 31-35]. Interestingly, we found MMC to be stable for at least $50 \mathrm{~min}$ at $50{ }^{\circ} \mathrm{C}$, thus inferring its stability during chemohyperthermia, which employs temperatures around $42{ }^{\circ} \mathrm{C}[13,33]$.

In the present stability study, we were not able to identify potential MMC degradation products resulting after the initial heated solubilization step. Degradants, not believed to be cytotoxic, appeared in trace quantities following a $24 \mathrm{~h}$ storage period at room temperature of MMC $0.4 \mathrm{mg} / \mathrm{mL}$ solutions prepared in sterile water [19]. MMC degradation is accelerated under strong acidic and alkaline conditions [36, 37], which were not present in the tested samples (pH approximately 7.0). MMC is a prodrug activated to alkylating species by quinone oxidoreductases [38]; however, under the study conditions, enzymes are not present to generate cytotoxic chemical species. Taken together, we can infer that the minimal degradation observed in the present study likely results in nontoxic species, although this has not been exclusively proven.

Some caution should be heeded by urologists and pharmacy staff in implementing changes in MMC preparation as described herein; there may be a small risk for increased MMC toxicities locally and systemically due to enhanced solubility, which would increase overall drug exposure. Furthermore, the pharmacodynamics of MMC, when prepared as described, are unknown when compared with conventional preparation methods; but, hypothetically, with greater drug content present due to greater solubilization, we predict an increase in cytotoxicity and efficacy. In addition, any changes in overall treatment outcomes following altered preparation methods, such as those reported in this paper, are unknown. We recommend clinicians closely monitor their patients for any significant changes in treatment-related toxicity and potential enhanced treatment effects following implementation of changes to conventional preparation methods. Nevertheless, preparation of MMC intravesicular solutions in pharmacologically optimized concentrations is achievable in the pharmacy and clinical setting.

\section{Conclusions}

This study demonstrated that MMC admixtures $(\geq 1.0 \mathrm{mg} /$ $\mathrm{mL}$ ), when prepared under conventional methods for intravesical delivery, do not achieve full solubilization, possibly leading to unwanted decreased exposure of drug to the bladder. We showed that MMC intravesical-intended solutions at pharmacologically optimized concentrations $(1.0$ and $2.0 \mathrm{mg} / \mathrm{mL})$ were physically and chemically stable up to $5 \mathrm{~h}$ while stored at $37^{\circ} \mathrm{C}$, following initial incubation at $50{ }^{\circ} \mathrm{C}$ in a hot water bath. We advise clinicians employing these changes to closely monitor their patients for any additional MMC toxicities (and possible improvements in clinical outcomes) that may result from the predicted enhancement of MMC exposure to the bladder.

\section{Compliance with Ethical Standards}

Funding This research received no specific grant from any funding agency in the public, commercial, or nonprofit sectors.

Conflicts of interest Alan Myers, Yan-Ping Zhang, Jitesh Kawedia, Ximin Zhou, Stacey Sobocinski, Michael Metcalfe, and Mark Kramer declare that they have no conflicts of interest. Colin Dinney is a Scientific/Advisory Committee Member at the University of Michigan Comprehensive Cancer Center (Ann Arbor, MI, USA) and for FKD Therapies Oy (Kuopio, Finland). Ashish Kamat has received grant funding from FKD Therapies Oy, Photocure (Princeton, NJ, USA), Merck (Kenilworth, NJ, USA) and Heat Biologics (Durham, $\mathrm{NC}$, USA), and has received consulting fees/honorarium from Cepheid (Sunnyvale, CA, USA), Photocure, Telesta Therapeutics (Montreal, QC, Canada), Sanofi (Gentilly, France), Merck, Abbott Molecular (Des Plaines, IL, USA), Theralase (Toronto, ON, Canada), Heat Biologics, Spectrum Pharmaceuticals (Henderson, NV, USA), Oncogenix (Bothell, WA, USA), and Pacific Edge Diagnostics (Hershey, PA, USA). All authors contributed sufficiently to the development, review, and revision of the manuscript.

Open Access This article is distributed under the terms of the Creative Commons Attribution-NonCommercial 4.0 International License (http://creativecommons.org/licenses/by-nc/4.0/), which permits any noncommercial use, distribution, and reproduction in any medium, provided you give appropriate credit to the original author(s) and the source, provide a link to the Creative Commons license, and indicate if changes were made.

\section{References}

1. Burger M, Catto JW, Dalbagni G, et al. Epidemiology and risk factors of urothelial bladder cancer. Eur Urol. 2013;63:234-41.

2. Casey RG, Catto JW, Cheng L, et al. Diagnosis and management of urothelial carcinoma in situ of the lower urinary tract: a systematic review. Eur Urol. 2015;67:876-88.

3. Begleiter A. Clinical applications of quinone-containing alkylating agents. Front Biosci. 2000;5:E153-71.

4. Bouffioux $\mathrm{C}$, Kurth $\mathrm{KH}$, Bono $\mathrm{A}$, et al. Intravesical adjuvant chemotherapy for superficial transitional cell bladder carcinoma: results of 2 European Organization for Research and Treatment 
of Cancer randomized trials with mitomycin $\mathrm{C}$ and doxorubicin comparing early versus delayed instillations and short-term versus long-term treatment. European Organization for Research and Treatment of Cancer Genitourinary Group. J Urol. 1995;153:934-41.

5. Friedrich MG, Pichlmeier U, Schwaibold H, et al. Long-term intravesical adjuvant chemotherapy further reduces recurrence rate compared with short-term intravesical chemotherapy and short-term therapy with Bacillus Calmette-Guerin (BCG) in patients with non-muscle-invasive bladder carcinoma. Eur Urol. 2007;52:1123-9.

6. Zargar H, Aning J, Ischia J, et al. Optimizing intravesical mitomycin $\mathrm{C}$ therapy in non-muscle-invasive bladder cancer. Nat Rev Urol. 2014;11:220-30.

7. Au JL, Badalament RA, Wientjes MG, et al. Methods to improve efficacy of intravesical mitomycin C: results of a randomized phase III trial. J Natl Cancer Inst. 2001;93:597-604.

8. Wientjes MG, Badalament RA, Au JL. Use of pharmacologic data and computer simulations to design an efficacy trial of intravesical mitomycin $\mathrm{C}$ therapy for superficial bladder cancer. Cancer Chemother Pharmacol. 1993;32:255-62.

9. Addeo R, Caraglia M, Bellini S, et al. Randomized phase III trial on gemcitabine versus mytomicin in recurrent superficial bladder cancer: evaluation of efficacy and tolerance. J Clin Oncol. 2010;28:543-8

10. Alfred Witjes J, Hendricksen K, Gofrit O, et al. Intravesical hyperthermia and mitomycin- $\mathrm{C}$ for carcinoma in situ of the urinary bladder: experience of the European Synergo working party. World J Urol. 2009;27:319-24

11. Arends TJ, Nativ O, Maffezzini M, et al. Results of a randomised controlled trial comparing intravesical chemohyperthermia with mitomycin $\mathrm{C}$ versus Bacillus Calmette-Guerin for adjuvant treatment of patients with intermediate- and high-risk non-muscle-invasive bladder cancer. Eur Urol. 2016;69(6):1046-52.

12. Colombo R, Da Pozzo LF, Salonia A, et al. Multicentric study comparing intravesical chemotherapy alone and with local microwave hyperthermia for prophylaxis of recurrence of superficial transitional cell carcinoma. J Clin Oncol. 2003;21:4270-6.

13. Colombo R, Salonia A, Leib Z, et al. Long-term outcomes of a randomized controlled trial comparing thermochemotherapy with mitomycin-C alone as adjuvant treatment for non-muscle-invasive bladder cancer (NMIBC). BJU Int. 2011;107:912-8.

14. Geijsen ED, de Reijke TM, Koning CC, et al. Combining mitomycin $\mathrm{C}$ and regional $70 \mathrm{MHz}$ hyperthermia in patients with nonmuscle invasive bladder cancer: a pilot study. J Urol. 2015;194:1202-8.

15. Kiss B, Schneider S, Thalmann GN, et al. Is thermochemotherapy with the Synergo system a viable treatment option in patients with recurrent non-muscle-invasive bladder cancer? Int J Urol. 2015;22:158-62.

16. Benvenuto JA, Anderson RW, Kerkof K, et al. Stability and compatibility of antitumor agents in glass and plastic containers. Am J Hosp Pharm. 1981;38:1914-8.

17. Mitomycin $\mathrm{C}$ for injection USP [package insert]. Durham: Accord Healthcare, Inc.; 2011.

18. Beijnen JH, van Gijn R, Underberg WJ. Chemical stability of the antitumor drug mitomycin $\mathrm{C}$ in solutions for intravesical instillation. J Parenter Sci Technol. 1990;44:332-5.

19. Kinast RM, Akula KK, DeBarber AE, et al. The degradation of mitomycin $\mathrm{C}$ under various storage methods. J Glaucoma. 2016;25:477-81.
20. Breyer BN, Whitson JM, Carroll PR, et al. Sequential intravesical gemcitabine and mitomycin $\mathrm{C}$ chemotherapy regimen in patients with non-muscle invasive bladder cancer. Urol Oncol. 2010;28: $510-4$.

21. United States Pharmacopeia. Particulate matter in injections (chapter 788). In: United States Pharmacopeia 34, National Formulary 29. Rockville: United States Pharmacopeial Convention, Inc.; 2011. p. 326-8.

22. Blessy M, Patel RD, Prajapati PN, et al. Development of forced degradation and stability indicating studies of drugs: a review. J Pharm Anal. 2014;4:159-65.

23. Kawedia JD, Zhang YP, Myers AL, et al. Physical and chemical stability of proflavine contrast agent solutions for early detection of oral cancer. J Oncol Pharm Pract. 2016;22:21-5.

24. Zhang Y, Trissel LA. Physical and chemical stability of pemetrexed solutions in plastic syringes. Ann Pharmacother. 2005;39:2026-8.

25. Zhang Y, Trissel LA. Physical and chemical stability of pemetrexed in infusion solutions. Ann Pharmacother. 2006;40:1082-5.

26. Zhang YP, Myers AL, Trinh VA, et al. Physical and chemical stability of reconstituted and diluted dexrazoxane infusion solutions. J Oncol Pharm Pract. 2014;20:58-64.

27. Seow HA, Penketh PG, Baumann RP, et al. Bioactivation and resistance to mitomycin C. Methods Enzymol. 2004;382:221-33.

28. Francoeur AM, Assalian A, Lesk MR, et al. A comparative study of the chemical stability of various mitomycin C solutions used in glaucoma filtering surgery. J Glaucoma. 1999;8:242-6.

29. Georgopoulos M, Vass C, Vatanparast Z, et al. Activity of dissolved mitomycin $\mathrm{C}$ after different methods of long-term storage. J Glaucoma. 2002;11:17-20.

30. Pankaj J, Murthy ZVP. Measurement of solubility of mitomycin $\mathrm{C}$ in ethanol-water solutions at different temperatures. Thermochimica Acta. 2012;545:163-73.

31. Di Stasi SM, Giannantoni A, Giurioli A, et al. Sequential BCG and electromotive mitomycin versus BCG alone for high-risk superficial bladder cancer: a randomised controlled trial. Lancet Oncol. 2006;7:43-51.

32. Di Stasi SM, Giannantoni A, Massoud R, et al. Electromotive versus passive diffusion of mitomycin $\mathrm{C}$ into human bladder wall: concentration-depth profiles studies. Cancer Res. 1999;59: 4912-8.

33. Lammers RJ, Witjes JA, Inman BA, et al. The role of a combined regimen with intravesical chemotherapy and hyperthermia in the management of non-muscle-invasive bladder cancer: a systematic review. Eur Urol. 2011;60:81-93.

34. Paroni R, Salonia A, Lev A, et al. Effect of local hyperthermia of the bladder on mitomycin $\mathrm{C}$ pharmacokinetics during intravesical chemotherapy for the treatment of superficial transitional cell carcinoma. Br J Clin Pharmacol. 2001;52:273-8.

35. van der Heijden AG, Verhaegh G, Jansen CF, et al. Effect of hyperthermia on the cytotoxicity of 4 chemotherapeutic agents currently used for the treatment of transitional cell carcinoma of the bladder: an in vitro study. J Urol. 2005;173:1375-80.

36. Beijnen JH, den Hartigh J, Underberg WJ. Quantitative aspects of the degradation of mitomycin $\mathrm{C}$ in alkaline solution. J Pharm Biomed Anal. 1985;3:59-69.

37. Beijnen JH, Underberg WJ. Degradation of mitomycin $\mathrm{C}$ in acidic solution. Int J Pharm. 1985;24:219-29.

38. Celli CM, Tran N, Knox R, et al. NRH:quinone oxidoreductase 2 (NQO2) catalyzes metabolic activation of quinones and anti-tumor drugs. Biochem Pharmacol. 2006;72:366-76. 